\title{
Identifying patients with axial spondyloarthritis in primary care: how useful are items indicative of inflammatory back pain?
}

\author{
A Braun, ${ }^{1}$ E Saracbasi, ${ }^{1}$ J Grifka, ${ }^{2}$ J Schnitker, ${ }^{3}$ J Braun ${ }^{1}$
}

${ }^{1}$ Rheumazentrum Ruhrgebiet

Herne, Germany

${ }^{2}$ Klinik und Poliklinik für

Orthopädie, Asklepios Klinikum

Bad Abbach, Germany

${ }^{3}$ Institut für angewandte

Statistik, Dr. Jörg Schnitker

GmbH, Bielefeld, Germany

\section{Correspondence to}

Professor J Braun,

Rheumazentrum Ruhrgebiet,

Landgrafenstr.15, 44652

Herne, Germany:

j.braun@rheumazentrum-

ruhrgebiet.de

Accepted 11 June 2011

Published Online First

5 August 2011

\begin{abstract}
Background The value of clinical items defining inflammatory back pain to identify patients with axial spondyloarthritis (SpA) in primary care is unclear.

Objective To identify predictive clinical parameters for a diagnosis of axial SpA in patients with chronic back pain presenting in primary care.

Methods Consecutive patients aged $<45$ years $(\mathrm{n}=950)$ with back pain for $>2$ months who presented to orthopaedic surgeons $(n=143)$ were randomised based on four key questions for referral to rheumatologists $(n=36)$ for diagnosis.

Results The rheumatologists saw 322 representative patients (mean age 36 years, 50\% female, median duration of back pain 30 months). 113 patients (35\%) were diagnosed as axial SpA (62\% HLA B27+), 47 (15\%) as ankylosing spondylitis (AS) and 66 (21\%) as axial non-radiographic SpA (nrSpA). Age at onset $\leq 35$ years, improvement by exercise, improvement with non-steroidal anti-inflammatory drugs, waking up in the second half of the night and alternating buttock pain were identified as most relevant for diagnosing axial SpA by multiple regression analysis. Differences between AS and nrSpA were detected. No single item was predictive, but $\geq 3$ items proved useful for good sensitivity and specificity by receiver operating characteristic modelling.

Conclusion This study shows that a preselection in primary care of patients with back pain based on a combination of clinical items is useful to facilitate the diagnosis of axial SpA.
\end{abstract}

The term spondyloarthritis ( $\mathrm{SpA}$ ) covers a heterogeneous group of rheumatic diseases characterised by common clinical symptoms such as inflammatory back pain (IBP) which is considered the leading symptom in patients with the condition. ${ }^{1}$ Patients with $\mathrm{SpA}$ have been divided into two subgroups according to the predominant symptoms, ${ }^{2} 3$ which can either be localised in the spine (axial SpA) or in the peripheral joints (peripheral SpA). Ankylosing spondylitis (AS), the prototype of axial SpA, is characterised by spinal stiffness. ${ }^{1}$ The other common differentiations used to diagnose or classify patients with SpA are the presence of a diseasedefining feature such as psoriasis, inflammatory bowel disease (IBD, Crohn's disease or ulcerative colitis) or the history of a triggering infection in the enteral or urogenital tract (reactive arthritis). In the absence of these features, the term 'undifferentiated SpA' (uSpA) has been used while, for patients with IBP but without structural changes in the sacroiliac joints and the spine, the term 'non-radiographic axial SpA' (nrSpA) is used. ${ }^{4}$ Not all patients with SpA will develop AS. 56

A significant delay in diagnosing AS has been reported. ${ }^{7}$ Thenew AssessmentofSpondyloArthritis international Society (ASAS) classification criteria ${ }^{2}$ ${ }^{3}$ are a step forward in making an earlier diagnosis of patients with axial SpA, but it is unclear whether they work in primary care. Possible screening tools for axial SpA including IBP and HLA B27 were proposed some years ago in patients with chronic back pain. ${ }^{8}$ Some of the proposed items were tested in a referral ${ }^{9}$ and a cohort study. ${ }^{10}$

The major clinical item in SpA is IBP, first defined in $1977 .{ }^{11} 12$ IBP has long been a central part of the classification criteria for $\mathrm{AS}^{13}$ and $\mathrm{SpA} .{ }^{14}$ Novel definitions for IBP have recently been proposed. ${ }^{11}$ 1516 In a population-based study, many false positive answers to questions on IBP were found in controls. ${ }^{17}$

Chronic back pain is a common symptom of patients presenting to GPs and orthopaedic surgeons. ${ }^{18}$ The general perception and approach to the diagnosis and management of AS has been reported to be in part inconsistent in primary care. ${ }^{19}$ There is limited knowledge on the prevalence of IBP due to SpA in primary care, but one study reported a prevalence of $5 \%$ among patients with chronic back pain, ${ }^{20}$ a percentage similar to that recently reported by chiropractitioners. ${ }^{21}$ of course, the prevalence of $\mathrm{SpA}$ in patients presenting to rheumatologists is likely to be significantly higher, reflecting the different pretest probability of $\mathrm{SpA} .^{22}$

The aim of this study was to test different IBPrelated clinical items in primary care.

\section{METHODS}

This study was designed as a prospective case ascertainment trial that included a stratification step based on prespecified recognition criteria leading to a randomised selection for referral to a rheumatologist. A total of 143 orthopaedic surgeons in private practice and 36 rheumatologists took part in the study. The time frame was April 2007 to June 2009 for screening and May 2007 to May 2009 for validation.

The study plan was to identify 1000 patients in primary care with chronic back pain for $>2$ months and $<10$ years in whom back pain first occurred between the ages of 16 and 45 years, and to refer to rheumatologists about 400 patients after stratification and randomised selection performed by an independent institute based on four prespecified recognition criteria: (1) morning stiffness >30 min; online under the BMJ Journals unlocked scheme, see http:// ard.bmj.com/info/unlocked.dtl 
(2) improvement by movement not by rest; (3) waking up in the second half of the night because of back pain; and (4) improvement with non-steroidal anti-inflammatory drugs (NSAIDs) within $48 \mathrm{~h}$. The answers to these questions, which were collected at the initial visit by the orthopaedic surgeons and transmitted for patient randomisation at the independent institute, were the basis for stratification into 16 cohorts. The rheumatologists, who were aware of the current classification criteria, made the final diagnosis. These data allowed validation of clinical questions and screening parameters and an analysis of the relative value of combinations of parameters.

Secondary criteria analysed were alternating buttock pain, a positive family history of SpA and extraspinal manifestations (presence or history of arthritis, enthesitis, psoriasis, IBD and HLA-B27).

\section{Statistical analysis}

The information was centrally collected at the Institut for Statistics of Dr Schnitker in Bielefeld, Germany where blinded decisions were made randomly as to which patients to refer to rheumatologists. Clinical information was sent to the institute where the statistical analyses were performed.

Descriptive statistics were made by standard methods. Logistic regression analysis with backward elimination was performed with several parameters as independent variables. The dependent variable was the diagnosis of axial SpA, AS and nrSpA by the rheumatologist. In addition, receiver operating characteristic (ROC) curves were calculated. HLA B27 was excluded from the analyses.

Table 1 Relative frequency of recognition criteria C1-C4 in the cohorts referred to the rheumatologist $(n=670)$

\begin{tabular}{|c|c|c|c|c|c|}
\hline Cohort & C1 & $\mathrm{C} 2$ & C3 & C4 & Frequency \\
\hline 1 & - & - & - & - & $21(3.1 \%)$ \\
\hline 2 & घ & - & - & - & $17(2.5 \%)$ \\
\hline 3 & - & $\square$ & - & - & $50(7.5 \%)$ \\
\hline 4 & - & - & घ & - & $26(3.9 \%)$ \\
\hline 5 & - & - & - & $\mathbf{\square}$ & $46(6.9 \%)$ \\
\hline 6 & घ & घ & - & - & $27(4.0 \%)$ \\
\hline 7 & $\square$ & - & घ & - & $8(1.2 \%)$ \\
\hline 8 & घ & - & - & $\square$ & $19(2.8 \%)$ \\
\hline 9 & - & घ & 曰 & - & 100 (14.9\%) \\
\hline 10 & - & घ & - & $\boldsymbol{\square}$ & $93(13.9 \%)$ \\
\hline 11 & - & - & घ & $\boldsymbol{\square}$ & $34(5.1 \%)$ \\
\hline 12 & च & घ & च & - & $39(5.8 \%)$ \\
\hline 13 & $\mathbf{\square}$ & घ & - & घ & $29(4.3 \%)$ \\
\hline 14 & घ & - & 口 & $\square$ & $14(2.1 \%)$ \\
\hline 15 & - & घ & $\mathbf{\square}$ & $\boldsymbol{\square}$ & $94(14.0 \%)$ \\
\hline 16 & घ & घ & $\square$ & घ & 53 (7.9\%) \\
\hline
\end{tabular}

Prespecified recognition criteria: $\mathrm{C} 1$, morning stiffness $>30 \mathrm{~min} ; \mathrm{C} 2$, improvement by movement not by rest; $\mathrm{C} 3$, waking up in the second half of the night because of back pain; $\mathrm{C4}$, improvement with non-steroidal anti-inflammatory drugs within $48 \mathrm{~h}$.

The filled boxes indicate that these items were present, the bars indicate absence.

\section{RESULTS}

\section{Description of patient populations studied}

A total of 1074 patients were included, of whom 950 could be analysed; 670 were referred to a rheumatologist of whom 334 attended, and 322 patients with complete data were available for analysis. The rheumatological examinations were performed a median of 20 days after the initial visit to primary care.

The relative frequency of the prespecified recognition criteria in the different subsets is shown in table 1 and the relative frequency of positive answers in table 2. Overall, there was no difference between the demographic characteristics of the patients referred to the rheumatologist and the total study population.

The characteristics of the 322 patients with complete data were: mean age $36 \pm 7.9$ years, $49.4 \%$ male, mean height of men $181 \pm 7 \mathrm{~cm}$, mean height of women $167 \pm 6 \mathrm{~cm}$, mean weight of men $85.6 \pm 14.5 \mathrm{~kg}$ and mean weight of women $67 \pm 16.7 \mathrm{~kg}$. The age at symptom onset was $32.2 \pm 7.4$ years and the mean duration of complaints was $44.2 \pm 38.1$ months.

The distribution within the age groups was 13 patients (4\%) aged $<20$ years, $67(21 \%)$ aged $21-30$ years, $134(42 \%)$ aged $31-40$ years, $104(32 \%)$ aged $41-50$ years and $4(1 \%)$ aged $>50$ years. Fifty-eight patients (18\%) reported having had back pain for $<6$ months, 43 (13\%) for 6-12 months, 51 (16\%) for 12-24 months, $84(26 \%)$ for $24-60$ months and 86 (27\%) for $>60$ months. Twenty-two (7\%) reported age at onset of $<20$ years, $49(15 \%)$ at age $21-25$ years, $49(15 \%)$ at age $26-30$ years, 85 $(26 \%)$ at age $31-35$ years, $69(21 \%)$ at age $36-40$ years and 48 $(15 \%)$ at age $41-45$ years.

\section{Patient diagnoses, demographics and clinical manifestations}

As shown in table 3, 113 patients were diagnosed with SpA (66 with $\mathrm{nrSpA}$ and 47 with definite AS) and 209 patients were diagnosed as non-SpA. The majority of the latter group had nonspecific lower back pain or degenerative disc disease.

The mean age of the patients with SpA was 36 years. The relative distribution of the different age groups was similar among the 113 patients with SpA and the 209 non-SpA patients $(9(8 \%)$ vs $13(6.2 \%)<20$ years, $44(38.9 \%)$ vs 54 (25.9\%) 20-30 years, $53(45.1 \%)$ vs 103 (49.3\%) 30-40 years and 9 (8\%) vs $39(18.7 \%)$ $>40$ years).

The age distribution between patients with AS and nrSpA was $26(55 \%)$ versus $27(41 \%)$ in those aged $<20-30$ years and $21(45 \%)$ versus $39(59 \%)$ in those aged $<30-45$ years.

Extraspinal manifestations were reported in $23.5 \%$, enthesitis/ heel pain in $11 \%$, arthritis/joint swelling without trauma in $7 \%$ and psoriasis in $6 \%$ of patients with SpA. A family history of AS and $\mathrm{SpA}$ was reported in $4 \%$ and $2 \%$ of patients, respectively.

\section{HLA B27 results}

HLA B27 was positive in 35/46 patients with AS (76.1\%), in $31 / 60$ with axial uSpA (51.7\%), in 66/106 patients with axial

Table 2 Relative frequency of positive answers for the entry criteria

\begin{tabular}{llll}
\hline & \multicolumn{2}{l}{ Cohort } & \\
\cline { 2 - 4 } Criteria & $\begin{array}{l}\text { Screening } \\
(\mathbf{n = 9 5 0 )}\end{array}$ & $\begin{array}{l}\text { Referral } \\
\text { (n=670) }\end{array}$ & $\begin{array}{l}\text { Validation } \\
\text { (n=334) }\end{array}$ \\
\hline C1: Morning stiffness > 30 min & $22.0 \%$ & $30.8 \%$ & $32.9 \%$ \\
C2: Improvement by movement not by rest & $60.4 \%$ & $72.4 \%$ & $65.6 \%$ \\
C3: Waking up in the second half of the night because of back pain & $38.9 \%$ & $54.9 \%$ & $46.4 \%$ \\
C4a: Improvement with NSAIDs within 48 h (in the whole cohort) & $44.6 \%$ & $57.0 \%$ & $55.4 \%$ \\
C4b: Improvement with NSAIDs within 48 h (if taken) & $73.6 \%$ & $80.9 \%$ & $76.4 \%$ \\
\hline
\end{tabular}


Table 3 Diagnoses of patients seen by the rheumatologist

\begin{tabular}{lcc}
\hline Cohort & N & $\%$ \\
\hline Total cohort referred & 322 & 100 \\
Axial SpA & 113 & 35.1 \\
Non-radiographic axial SpA & 66 & 20.5 \\
$\quad$ Undifferentiated SpA & 55 & 83.3 \\
SpA associated with psoriasis & 5 & 7.6 \\
Reactive SpA & 3 & 5.0 \\
SpA associated with IBD & 3 & 5.0 \\
AS & 47 & 14.6 \\
Non-SpA back pain & 209 & 64.9 \\
\hline
\end{tabular}

AS, ankylosing spondylitis; IBD, inflammatory bowel disease; non-SpA, no spondyloarthritis; $\mathrm{SpA}$, spondyloarthritis.

SpA (62.3\%) and in 22/184 patients with other causes of back pain (12\%). HLA B27 was not determined in 7 patients with SpA and 25 non-SpA patients. The prevalence of HLA B27 in the German population is about $9 \% .{ }^{17}$

\section{Comparative performance of different items to predict SpA Sensitivity, specificity and likelihood ratios of the most relevant items}

The performance of the prespecified recognition criteria for the prediction of AS, nrSpA and axial SpA showed a sensitivity of $70.2 \%, 39.4 \%$ and $52.2 \%$, respectively, a specificity of $74.6 \%$ and a quality of $72.7 \%, 57.3 \%$ and $63.7 \%$, respectively. The positive likelihood ratio (LR+) for axial SpA was 2.8 and the negative likelihood ratio (LR-) was 0.64.

The most useful items and their combinations are shown in table 4 . This table shows that single items are of limited value and that the combination of any three items does not substantially increase the likelihood of axial SpA.

While the LR + values were all $<3$, the LR- of improvement by NSAIDs, age $\leq 35$ years and $\geq 3$ criteria fulfilled indicated possible usefulness in primary care. This was further analysed by ROC curve analyses (see below).

\section{Regression analyses}

The main results of the multivariate logistic regression analysis are shown in table 5. In general, ORs were higher for AS than for $\mathrm{nrSpA}$ and there were other differences between the two (see below). The OR for the whole group of patients with axial SpA was 1.2-3.6, with different levels of significance.

For axial $\mathrm{SpA}$, the $\mathrm{p}$ values of the items age at onset $\leq 35$ years, improvement by NSAIDs and by movement, waking up in the second half of the night and alternating buttock pain indicated a significant value for identifying patients with axial SpA in primary care, while other items known to be characteristic for SpA were not significant. For AS, the items listed for axial SpA were the same but, for nrSpA, different items (enthesitis and psoriasis) were relevant in addition to age at onset $\leq 35$ years.

\section{ROC curve analyses}

The ROC curves were calculated on the basis of items with significant results in the regression analysis for AS, early axial $\mathrm{SpA}$ and the whole group of axial SpA. An example is shown in figure1.

- For a diagnosis of axial SpA, ROC curve analysis (figure 1) showed that, if $\geq 4$ criteria were present, the sensitivity was $47.8 \%$, the specificity was $86.1 \%$ (area under curve (AUC) $71.3 \%), \mathrm{LR}+3.4, \mathrm{LR}-0.6$.

- For a diagnosis of AS, ROC curve analysis showed that, if $\geq 3$ criteria were present, the sensitivity was $57.4 \%$, specificity was $85.6 \%$ (AUC 75.7\%), LR+ 4.0, LR- 0.5. If $\geq 2$ criteria were present, the sensitivity was $85.1 \%$, specificity was $46 \%, \mathrm{LR}+1.6, \mathrm{LR}-0.6$ (data not shown).

- For a diagnosis of nrSpA, ROC curve analysis showed that, if $\geq 1$ criterion was present, the sensitivity was $81.8 \%$, specificity $35.9 \%$ (AUC $64.9 \%$ ), LR+ 1.3, LR- 0.5 . If $\geq 2$ criteria were present, the sensitivity was $24.2 \%$ and the specificity $57 \%$ (data not shown).

Thus, there were major differences between patients with AS and $\mathrm{nrSpA}$.

\section{Differences between $\mathrm{AS}$ and $\mathrm{nrSpA}$}

For a diagnosis of AS the following four parameters always proved to be relevant while this was not the case in the nrSpA group:

- Improvement of back pain in motion, not at rest.

- Waking up during the second half of the night.

- Improvement with NSAIDs within 48 h.

- Alternating buttock pain.

For the nrSpA group the following parameters were more relevant:

- Age at onset $\leq 35$ years.

- History of enthesitis.

- History of psoriasis.

In contrast, male gender, duration of chronic back pain $>30$ months, a family history of SpA, a history of uveitis, a history of IBD, morning stiffness $>30$ min (C1) did not appear to be relevant in any model or criteria set.

The quality of the models was highest for AS, followed by axial SpA and nrSpA.

\section{DISCUSSION}

This is the first study to analyse prospectively the predictive performance of clinical items for diagnosing axial SpA in a primary care setting. In Germany, most patients with back pain will see an orthopaedic surgeon as their first contact with the health system. This does not mean that GPs and physical therapists will not also see such patients, but these healthcare professionals were not included in this study. It also needs to be stressed that we did not only include patients who visited a physician with back pain for the first time.

The results of this study show that asking single specific SpArelated questions in primary care is of no value for a diagnosis of patients with axial $\mathrm{SpA}$ and that specific combinations are much more useful. Furthermore, we have identified important differences between patients with established AS and those with $\mathrm{nrSpA}$.

Our data confirm the results of earlier studies which also suggested that single screening parameters are of very limited value and that combinations of parameters perform better. ${ }^{10}$ It is important to stress that this dataset has been obtained in a prespecified population of relatively young patients with chronic back pain and not in the general population. This is consistent with the major aim of the study, which was to develop a good tool to facilitate an early diagnosis of axial SpA.

The best likelihood ratio for a diagnosis of axial SpA calculated (excluding HLA B27) was obtained with the following five items: age at onset $\leq 35$ years, waking up in the second half of the night, alternating buttock pain, improvement by NSAIDs within 48 h or no NSAID and improvement by movement not rest. It will be necessary to test this proposal prospectively to further determine its usefulness.

Some findings of this study deserve special comment. It is noteworthy that the age cut-off for SpA was lower in our study 
Table 4 Sensitivity and specificity of the main entry criteria and other SpA-specific items for AS and axial SpA in primary care

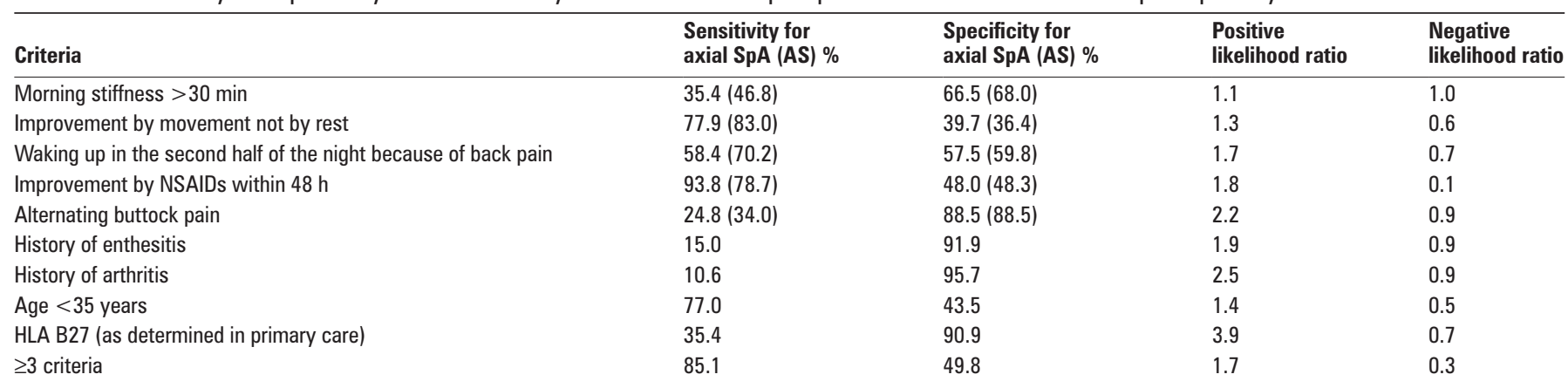

AS, ankylosing spondylitis; NSAID, non-steroidal anti-inflammatory drug; SpA, spondyloarthritis.

Table 5 Odds ratios (OR) of relevant items for a diagnosis of axial $\mathrm{SpA}$ : results of logistic regression analysis

\begin{tabular}{|c|c|c|c|}
\hline & AS & Non-radiographic axial SpA & Axial SpA \\
\hline Age $\leq 35$ years & $2.5(p=0.03)$ & $2.8(p=0.03)$ & $2.6(95 \% \mathrm{Cl} 1.5$ to 4.5$)(p=0.0009)$ \\
\hline Alternating buttock pain & $3.3(p=0.005)$ & $2.0(p=0.1)$ & $2.7(95 \% \mathrm{Cl} 1.4$ to 5.5$)(p=0.003)$ \\
\hline Improvement by NSAIDs within $48 \mathrm{~h}$ or no NSAID & $2.9(p=0.01)$ & NS & $1.2(95 \% \mathrm{Cl} 0.7$ to 2.2$)(p=0.004)$ \\
\hline Waking up in the second half of the night & $3.0(p=0.005)$ & NS & $1.9(95 \% \mathrm{Cl} 1.1$ to 3.2$)(p=0.001)$ \\
\hline Improvement by movement not by rest & $2.0(p=0.1)$ & $1.9(p=0.07)$ & $1.9(95 \% \mathrm{Cl} 1.0$ to 3.4$)(p=0.03)$ \\
\hline History of psoriasis & NS & $3.6(p=0.02)$ & $2.1(95 \% \mathrm{Cl} 0.7$ to 6.4$)(p=0.2)$ \\
\hline History of enthesitis & NS & $2.7(p=0.03)$ & $2.3(95 \% \mathrm{Cl} 1.0$ to 5.1$)(p=0.06)$ \\
\hline History of anterior uveitis & $7.2(p=0.07)$ & NS & $3.6(95 \% \mathrm{Cl} 0.5$ to 25.3$)(p=0.2)$ \\
\hline History of arthritis & $3.4(p=0.079$ & $2.5(p=0.1)$ & $2.6(95 \% \mathrm{Cl} 0.9$ to 7.1$)(p=0.06)$ \\
\hline Family history of SpA & NS & $2.5(p=0.1)$ & $2.3(95 \% \mathrm{Cl} 0.8$ to 6.6$)(p=0.1)$ \\
\hline
\end{tabular}

AS, ankylosing spondylitis; NS, not significant; NSAID, non-steroidal anti-inflammatory agent; SpA, spondyloarthritis.

than earlier proposals for IBP. ${ }^{11}$ This makes sense since the mean age at onset of AS is 26 years. ${ }^{1}$ Currently used IBP criteria should be re-evaluated on this basis, having in mind that this will probably be mainly helpful in identifying patients with a high likelihood of developing AS, and that this may be different in patients with nrSpA including those with a slowly progressive course of disease (see below). ${ }^{6}$

On the other hand, the absence of the classic IBP criterion of morning stiffness was unexpected. Alternating buttock pain is often suggested as a possible contributor ${ }^{15}$ since, although not very sensitive, this item is rather specific and is now shown in a primary care setting. However, a combination with other items is necessary.

Waking up in the second half of the night was not part of the original criteria set for a definition of $\mathrm{IBP}^{11}$ but was introduced later. $^{23}$ This item is also useful in primary care, again mainly when combined with other items.

A good response to NSAIDs ${ }^{24}$ has become increasingly established as part of the classification criteria for axial SpA, ${ }^{3}$ as confirmed in this study. The results of a recent meta-analysis on the efficacy of NSAIDs in non-specific low back pain ${ }^{25}$ support this proposal. However, as our study also shows, not all the patients had taken NSAIDs. Thus, a negative answer to the question concerning improvement by NSAIDs may simply indicate that the patient had not taken the medication. This needs to be taken into account in future studies. Improvement by movement, although not really a medical intervention, is also related to a change in patient behaviour (moving around instead of resting).

Another important finding is that the items that perform best in the prediction of axial SpA differed between established AS and nrSpA. Both enthesitis and psoriasis were found to be useful. We were surprised that enthesitis was a significant item because, although somewhat characteristic of $\mathrm{SpA},{ }^{26}$ it is not an easy item for patients to understand. The same is true for psoriasis, which is a rather frequent disease. The difference between AS and nrSpA may be explained by observational studies suggesting that not all patients with nrSpA develop AS. ${ }^{5} 6$ Thus, axial SpA is not only a disease continuum from early (nrSpA) to advanced disease (AS), but also a covering term for patients who might never develop structural changes in the sacroiliac joints and/or the spine. This has also been suggested by recent studies on anti-tumour necrosis factor therapy in 'early'27 and $\mathrm{nrSpA},{ }^{28}$ where the mean age of the patients differed (28 and 38 years, respectively).

The design and methodology used in this study ensured that the patients seen by the rheumatologists were representative, as shown in table 1 . However, the prevalence of the prespecified recognition items was slightly higher in the referral population, which may have led to more patients with SpA being seen by the rheumatologist (see below). The selection of the entry criteria was based on published criteria for IBP and expert opinion. Because of the low sensitivity of the item 'alternating buttock pain', we decided to use a good response to NSAIDs as a major criterion because of the expected high sensitivity, and this was clearly confirmed by the data obtained. We were surprised by the relatively bad performance of morning stiffness for $>30$ min which was only stated by about $22 \%$ of patients. The other two items performed as expected. As shown in table 2, we managed to include patients in the appropriate age groups, the planned gender ratio was met and the patient numbers planned were included. The majority of patients were seen within 3 weeks by the rheumatologists, but they appeared to have some problems with their capacity to see referral patients, which is why fewer than 400 patients were seen by the experts who were in charge of the diagnosis. These colleagues had been informed about the new ASAS criteria ${ }^{2}{ }^{3}$ and the established AS criteria, ${ }^{13}$ but we did not systematically check whether they were correctly applied. This is a possible weakness of the study, but the 


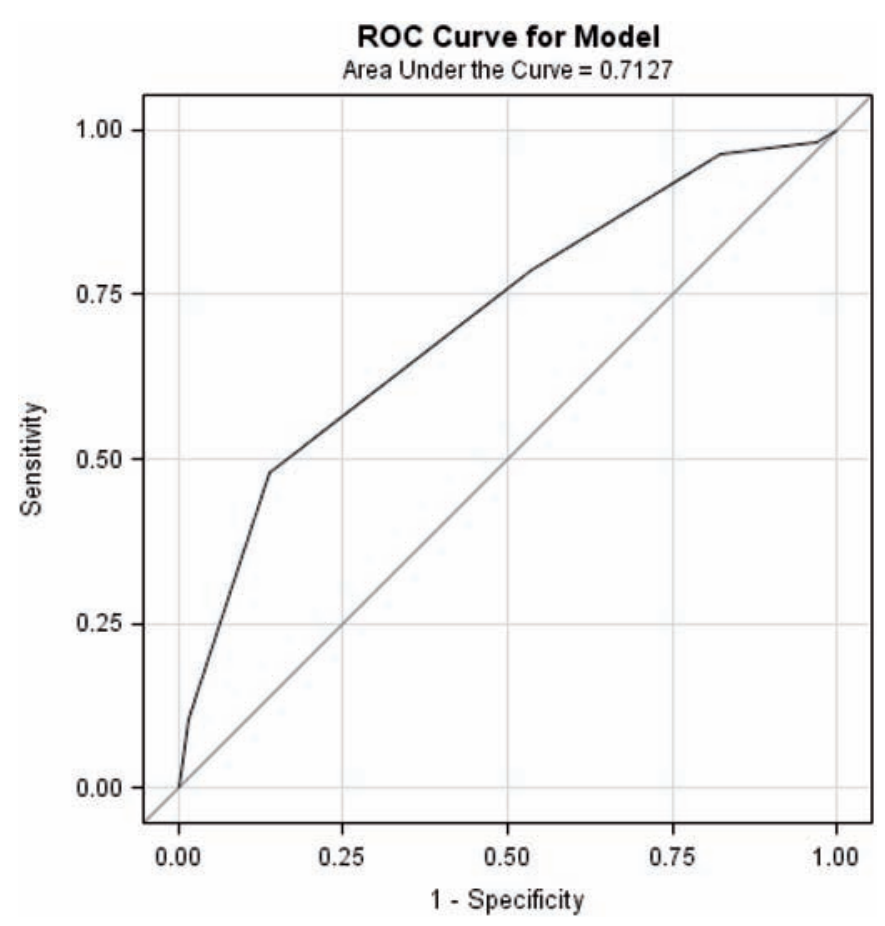

Figure 1 Criteria for the recognition of axial SpA. Age at onset $\leq 35$ years; wakening up in the second half of the night; alternating buttock pain; improvement by NSAIDs within $48 \mathrm{~h}$ or no NSAID; improvement by movement, not rest.

The sensitivities and specificities for $\geq 4$ criteria were 47.8 and $86.1 \%$, for $\geq 3$ criteria 78.8 and $46.4 \%$, and $\geq 2$ criteria 96.5 and $17.0 \%$, respectively.

NSAID non-steroidal anti-inflammatory drug; SpA, axial spondyloarthritis.

relatively high percentage of patients with HLA B27+ axial SpA suggests that most of the diagnoses were correct. Furthermore, the gold standard for making diagnoses of axial SpA and AS is the rheumatologists' expert opinion. ${ }^{2} 314$

On this basis, about one-third of the patients seen were diagnosed as axial SpA, somewhat more with the non-radiographic early form than with the more advanced form, fulfilling the New York criteria for AS. Interestingly, many more patients in the former group were undifferentiated.

Although the one previous study with a somewhat similar design had also reported a relatively high success rate with a screening design for IBP, ${ }^{10}$ we had not necessarily expected this result because we had chosen a sophisticated randomisation strategy. There are two possible explanations for this: (1) the prevalence of axial SpA in the population is known to be rather high ${ }^{29} 30$ and the prevalence of AS in an orthopaedic setting was almost $20 \%, 31$ and (2) the doctors in primary care may have preselected patients with a higher probability of SpA (even though we asked for consecutive patients with back pain); however, due to our randomisation strategy, we think this is unlikely. For future cohort studies we believe that similar strategies should be used to identify patients with SpA in primary care. Interestingly, two new studies presented at the American College of Rheumatology 2010 showed similar results regarding the prevalence of axial SpA in primary care. ${ }^{32} 33$

Another relevant finding of this study is that different items and different combinations of items perform differently for the different SpA subsets studied. Since we consider this an important new finding, we have presented these results in detail.
What does this mean with regard to identifying patients with suspected axial SpA as early as possible? In general one would like to have a tool with very good sensitivity to identify as many patients as possible but, on the other hand, the capacity to see patients may be limited and a high specificity may be more important. We have presented our results in relation to both points of view so the rheumatologist, in cooperation with GPs or orthopaedic surgeons, can choose which way to go. Since it seems easier and more useful to stick to the criteria for axial SpA rather than to look at AS and nrSpA differently, we propose using these criteria for calculations for the selection process (figure 1). Thus, in settings with very good capacity, the preferred strategy would be to go for $2 / 5$ criteria with a sensitivity of $96.5 \%$ and a specificity of $17 \%$, which means that five patients with chronic back pain will have to be seen to make a diagnosis of axial SpA in one. This strategy seems to guarantee that almost all patients with axial SpA can be identified. In settings with limited capacity the strategy could be to go for $4 / 5$ criteria, in which case almost every patient seen will have axial SpA but about half the patients will be lost. The intermediate strategy with $3 / 5$ criteria has a sensitivity of $79 \%$ and a specificity of $47 \%$, which means that only $20 \%$ of patients with axial $\mathrm{SpA}$ would be lost and a diagnosis is likely to be made in every second patient.

It remains to be seen whether strategies including HLA B27 testing in primary care will further improve the performance of the clinical parameters. This will be analysed in a separate paper.

Finally, it must be stressed that the results of this study are only valid in a primary care setting in Germany and therefore we are not discussing diagnostic or classification criteria but rather tools that can be used to preselect patients who need to be seen by the rheumatologist. The proposed strategies based on the results of this study should be further evaluated prospectively in other countries.

Acknowledgements The authors thank Professor D van der Heijde, Professor $\mathrm{J}$ Sieper, Dr J Listing and Dr M Vennemann for their useful comments.

Funding The study was sponsored by an unrestricted grant from Abbott, Germany. The company had no influence on the study design, results and analyses.

Competing interests None.

Ethics approval Approval of the ethical committee of the Aerztekammer WestfalenLippe at the University of Muenster was obtained and patients gave written informed consent before inclusion in the study.

Provenance and peer review Not commissioned; externally peer reviewed.

\section{REFERENCES}

1. Braun J, Sieper J. Ankylosing spondylitis. Lancet 2007;369:1379-90.

2. Rudwaleit M, Landewé R, van der Heijde D, et al. The development of Assessment of Spondyloarthritis International Society (ASAS) classification criteria for axial spondyloarthritis (part I): classification of paper patients by expert opinion including uncertainty appraisal. Ann Rheum Dis 2009;68:770-6.

3. Rudwaleit M, van der Heijde D, Landewé R, et al. The development of Assessment of Spondyloarthritis International Society (ASAS) classification criteria for axial spondyloarthritis (part II): validation and final selection. Ann Rheum Dis 2009;68:777-83.

4. Zochling J, Brandt J, Braun J. The current concept of spondyloarthritis with special emphasis on undifferentiated spondyloarthritis. Rheumatology (Oxford) 2005:44:1483-91.

5. Uppal SS, Pande I, Singh G, et al. Profile of HLA-B27-related 'unclassifiable' seronegative spondyloarthropathy in females and its comparison with the profile in males. Br J Rheumatol 1995; 34:137-40.

6. Mau W, Zeidler H, Mau R, et al. Clinical features and prognosis of patients with possible ankylosing spondylitis. Results of a 10-year followup. J Rheumatol 1988;15:1109-14.

7. Feldtkeller E, Khan MA, van der Heijde D, et al. Age at disease onset and diagnosis delay in HLA-B27 negative vs. positive patients with ankylosing spondylitis. Rheumatol Int 2003;23:61-6. 
8. Sieper J, Rudwaleit M. Early referral recommendations for ankylosing spondylitis (including pre-radiographic and radiographic forms) in primary care. Ann Rheum Dis 2005;64:659-63.

9. Rudwaleit M, Haibel H, Baraliakos X, et al. The early disease stage in axial spondylarthritis: results from the German Spondyloarthritis Inception Cohort. Arthritis Rheum 2009;60:717-27.

10. Brandt HC, Spiller I, Song $\mathrm{H}$, et al. Performance of referral recommendations in patients with chronic back pain and suspected axial spondyloarthritis. Ann Rheum Dis 2007:66:1479-84.

11. Braun J, Inman R. Clinical significance of inflammatory back pain for diagnosis and screening of patients with axial spondyloarthritis. Ann Rheum Dis 2010;69:1264-8.

12. Calin A, Porta J, Fries JF, et al. Clinical history as a screening test for ankylosing spondylitis. JAMA 1977;237:2613-14.

13. van der Linden S, Valkenburg HA, Cats A. Evaluation of diagnostic criteria for ankylosing spondylitis. A proposal for modification of the New York criteria. Arthritis Rheum 1984;27:361-8.

14. Dougados M, van der Linden S, Juhlin R, et al. The European Spondylarthropathy Study Group preliminary criteria for the classification of spondylarthropathy. Arthritis Rheum 1991;34:1218-27.

15. Rudwaleit M, Metter A, Listing J, et al. Inflammatory back pain in ankylosing spondylitis: a reassessment of the clinical history for application as classification and diagnostic criteria. Arthritis Rheum 2006;54:569-78.

16. Sieper J, van der Heijde DM, Landewé RB, et al. New criteria for inflammatory back pain in patients with chronic back pain: a real patient exercise of the assessment by experts from the Assessment of SpondyloArthritis international Society (ASAS). Ann Rheum Dis 2009;68:784-8.

17. Braun J, Bollow M, Remlinger $G$, et al. Prevalence of spondylarthropathies in HLAB27 positive and negative blood donors. Arthritis Rheum 1998;41:58-67.

18. Deyo RA, Mirza SK, Martin BI. Back pain prevalence and visit rates: estimates from U.S. national surveys, 2002. Spine 2006;31:2724-7.

19. Underwood MR, Dawes P. Inflammatory back pain in primary care. $\mathrm{Br} \mathrm{J}$ Rheumatol 1995:34:1074-7.

20. O'Shea FD, Boyle E, Salonen DC, et al. Inflammatory and degenerative sacroiliac join disease in a primary back pain cohort. Arthritis Care Res (Hoboken) 2010;62:447-54.
21. Jois RN, Macgregor AJ, Gaffney K. Recognition of inflammatory back pain and ankylosing spondylitis in primary care. Rheumatology (Oxford) 2008:47:1364-6.

22. Rudwaleit M, van der Heijde D, Khan MA, et al. How to diagnose axial spondyloarthritis early. Ann Rheum Dis 2004;63:535-43.

23. Gran JT. An epidemiological survey of the signs and symptoms of ankylosing spondylitis. Clin Rheumatol 1985;4:161-9.

24. Amor B. [Response to treatment as an aid to diagnosis]. Rev Rhum Mal Osteoartic 1992;59(6 Pt 2):3S-6S.

25. Roelofs PD, Deyo RA, Koes BW, et al. Nonsteroidal anti-inflammatory drugs for low back pain: an updated Cochrane review. Spine 2008;33:1766-74.

26. McGonagle D, Gibbon W, Emery P. Classification of inflammatory arthritis by enthesitis. Lancet 1998;352:1137-40

27. Barkham $\mathbf{N}$, Keen $\mathrm{HI}$, Coates $\mathrm{LC}$, et al. Clinical and imaging efficacy of infliximab in HLA-B27-Positive patients with magnetic resonance imaging-determined early sacroiliitis. Arthritis Rheum 2009;60:946-54.

28. Haibel H, Rudwaleit M, Listing J, et al. Efficacy of adalimumab in the treatment of axial spondylarthritis without radiographically defined sacroiliitis: results of a twelveweek randomized, double-blind, placebo-controlled trial followed by an open-label extension up to week fifty-two. Arthritis Rheum 2008;58:1981-91.

29. Helmick CG, Felson DT, Lawrence RC, et al. Estimates of the prevalence of arthritis and other rheumatic conditions in the United States. Part I. Arthritis Rheum 2008:58:15-25

30. Onen F, Akar S, Birlik M, et al. Prevalence of ankylosing spondylitis and related spondyloarthritides in an urban area of Izmir, Turkey. J Rheumatol 2008;35:305-9.

31. Jajić I. The role of HLA-B27 in the diagnosis of low back pain. Acta Orthop 1979;50:411-13.

32. Van Hoeven L, Luime J, Han $\mathrm{H}$, et al. Striking prevalence of axial spondyloarthritis in primary care patients with chronic low back pain; a cross-sectional study. Arthritis Rheum 2010;62(Suppl 10):2180.

33. Poddubnyy D, Vahldiek J, Spiller I, et al. Screening for axial spondyloarthritis in a primary care: comparison of two strategies in a multicenter prospective study. Arthritis Rheum 2010;62(Suppl 10):2181. 